\title{
Tribology behavior of a lubricant with nano-diamond particles on steel
}

\author{
SUNG-WAN HWANG ${ }^{1}$, SUNG-CHUL CHANG ${ }^{1}$, TE ZHANG ${ }^{1}$, HO-KYUNG KIM*22 \\ ${ }^{1}$ Dept. of Automotive Engineering, Graduate School, Seoul National University of Science and Technology \\ ${ }^{2}$ Dept. of Mechanical and Automotive Engineering, Seoul National University of Science and Technology \\ 172 Kongneung-dong, Nowon-ku, Seoul, 139-722, Korea \\ *Corresponding author: kimhk@seoultech.ac.kr
}

\begin{abstract}
A pin-to-disc wear testing machine was used in order to investigate the wear characteristics of a lubricant with nano-diamond (ND) particles. The applied loads were $30 \mathrm{~N}, 40 \mathrm{~N}, 50 \mathrm{~N}$ and $60 \mathrm{~N}$ and the sliding speed was $0.3 \mathrm{~m} / \mathrm{s}$. The wear tests were run with a sliding distance of $24 \mathrm{~km}$. The friction coefficients and wear loss of S45C specimens were tested in a commercial oil (5W-40) with different ND concentrations ranging from 0 to $0.02 \mathrm{wt}$.\%. The addition of ND particles to commercial oil was found to reduce the coefficient of friction for S45C steel. ND particles as a solid additive in oil lubricants were found to improve the tribological behavior of S45C carbon steel. For the S45C steel, the best concentration was found to be $\mathbf{0 . 0 0 7 5}$ wt.\% for both the anti- wear and friction reduction performance capabilities.
\end{abstract}

Keywords: Nano-diamond particles, Tribology behavior, Wear loss, Friction coefficient

\section{INTRODUCTION}

Generally, the tribological regimes for sliding lubricated surfaces are broadly categorized into the solid/boundary lubrication, mixed lubrication, and fluid film lubrication types. Oil additives are extensively used for boundary and fluid film lubrication applications. These additives form an adsorption layer on metal surfaces to prevent the direct contact of rubbing pairs. Over the last few years, interest in applications of several types of nanoparticles as lubricant additives has steadily grown due to the demonstrated reduction in friction and wear when using nanoparticle-containing lubricants [1-4]. Among these additives, nano-diamond (ND) particles have recently been shown to be promising candidates for reducing wear and friction both economically and effectively.

There have been many investigations of the tribological properties of lubricants with ND particles added. A large number of papers have reported that the addition of ND particles to a lubricant can effectively reduce wear and friction by acting as ball bearings between two mutually sliding surfaces $[1,5-8]$. The friction-reduction and anti-wear behaviors are dependent on the characteristics of the concentration and test alloys. For example, Wu et al. investigated the friction and wear characteristics of lubricants with $\mathrm{CuO}, \mathrm{TiO}_{2}$ and diamond nanoparticles [5]. They reported a ball bearing effect with these particles between two rubbing surfaces, resulting in excellent load-carrying capacities and, anti-wear and friction-reduction properties. Chu et al. studied the tribological characteristics and scuffing resistance of ND lubricants on SKD11 die steel under various sliding speeds and loads [6]. They proved that the addition of ND particles to a lubricant is effective for reducing scuffing and friction. Chou and Lee [7] studied the rheological behavior and tribological performance of lubricants with ND particles. They found that ND particles made the wear tracks of aluminum alloy smoother by polishing the contact asperities and thus increasing the friction and wear. However, for carbon steel pairs, this additive reduced the friction force and the wear but made the wear tracks rougher.

There are conflict reports of the effects of ND lubricants on anti-wear performance capabilities and tribological characteristics. The aim of the present study is experimentally to investigate the anti-wear performance of lubricants with and without ND. Lubricants containing ND particles at various concentrations $(0$ $\sim 0.02$ wt.\%) were used to evaluate the friction reduction and anti-wear abilities of these particles.

\section{EXPERIMENTAL}

A pin-to-disc wear test was used in order to investigate the friction-reduction and anti-wear abilities of lubricant with ND particles. The friction coefficient between rubbing specimens was measured. For the wear test, the pin specimen was a steel ball (SUJ-2) with a diameter of $4 \mathrm{~mm}$. The lower disc specimen was $\mathrm{S} 45 \mathrm{C}$ steel with corresponding outer and inner diameters of $40 \mathrm{~mm}$ and $24 \mathrm{~mm}$ and with a thickness of $5 \mathrm{~mm}$. The disc specimens were polished using $0.05 \mu \mathrm{m}$ aluminum oxide powder before the wear tests. The wear tests were conducted at a mean sliding speed of $0.3 \mathrm{~m} / \mathrm{s}$ under loads of $30 \mathrm{~N}, 40 \mathrm{~N}, 50 \mathrm{~N}$, and $60 \mathrm{~N}$. The total sliding 
distance for every test was fixed as $24 \mathrm{~km}$. The weight of the specimen was measured before and after the test using a precision balance with accuracy of $0.1 \mathrm{mg}$ in order to measure the wear rate.

The ND particles used in this study were provided by a commercial source (Daehwa-Alloytech, Korea). Fig. 1 shows a TEM image of the diamond particles used in the ND additive. The average particle diameter was $5 \pm$ $0.45 \mathrm{~nm}$. This ND lubricant additive was added to a commercial diesel engine lubricant (5W-40) at various weight percentages. Five oil samples with different concentration of the ND lubricant additive $(0.005 \mathrm{wt} . \%$, 0.0075 wt.\%, 0.01 wt.\%, 0.015 wt.\%, and 0.02 wt.\%) and a base oil without ND particles were tested in an effort to investigate the tribological performance of friction and anti-wear.

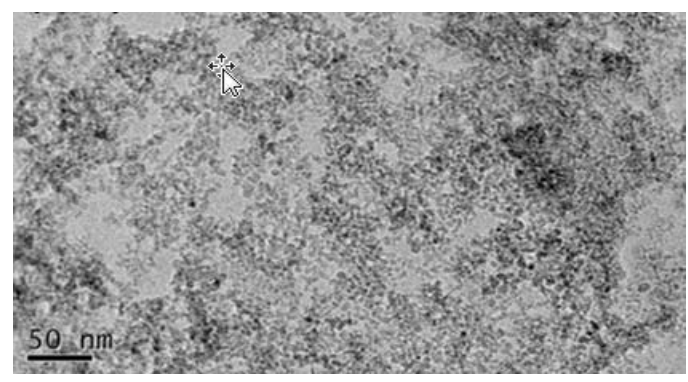

Fig. 1 TEM micrograph of cluster ND powders in oil

\section{EXPERIMENTAL RESULTS AND DISCUSSION}

In order to evaluate the tribological performance capabilities of the lubricant with different ND additive concentrations, the average wear loss for each ND additive concentration was determined by taking the average value after six tests after a distance of $24 \mathrm{~km}$ under a contact force of $30 \mathrm{~N} \sim 60 \mathrm{~N}$. Fig. 2 shows the average wear loss for $5 \mathrm{~W}-40$ with six ND additive concentrations. The wear loss increased with the increment of the contact force. The wear loss was reduced by the ND additive concentration at a contact force of $30 \mathrm{~N}$. Fig. 2 indicates that the additive concentration of $0.01 \mathrm{wt} . \% \mathrm{ND}$ is most favorable for reducing wear loss, resulting in a $70 \%$ reduction, compared to the case without ND particles. However, the wear loss increased when using the lubricants with ND particles at contact forces higher than $30 \mathrm{~N}$, compared to the lubricant without ND particles. Specifically, the lubricant with $0.015 \mathrm{wt} . \% \mathrm{ND}$ particles exhibited significant wear loss at a contact force higher than $30 \mathrm{~N}$ due to the fact that the ND particles acted as an abrasive when sliding occurred.

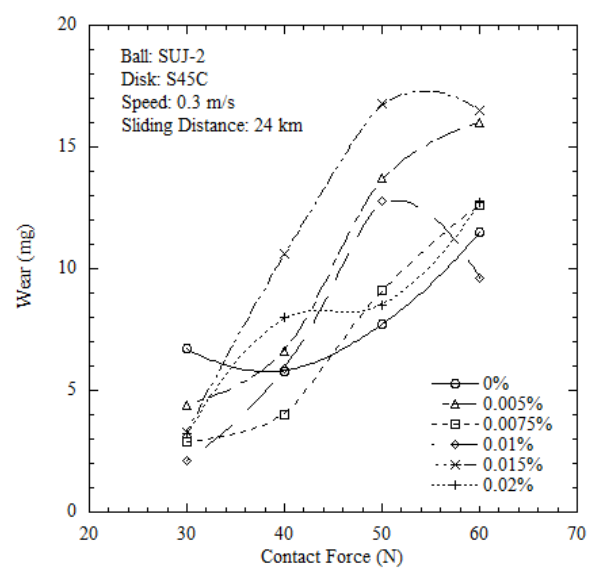

Fig. 2 Wear loss of disc as a function of contact force after $24 \mathrm{~km}$ wear test

In general, wear loss depends on the contact pressure, abrasive particle used, and the relative hardness of the two rubbing materials. For example, an anti-wear performance study of a lubricant with ND particles on low carbon steel and bearing steel [6] reported that non-heat treated low-carbon steel with a hardness of $200 \mathrm{H}_{\mathrm{v}}$ exhibited increased wear loss, whereas, the bearing steel exhibited decreased wear loss. The researchers argued the ND particles were imbedded into the surfaces and that there was two-body abrasion, resulting in significant wear loss in the low-carbon steel. However, Kim et al. reported that low-carbon steel with a hardness of approximately $500 \mathrm{H}_{\mathrm{v}}$ showed significantly reduced wear loss when using a lubricant with ND particles [9]. Their result stands in contrast to the present experimental results. They argued that the reason behind the reduced wear loss is the bearing effect of ND particles between rubbing surfaces in the case of steel during sliding. The hardness of contact surfaces is high enough to sustain the particles, and three-body abrasion 
occurred between the surfaces when sliding occurred.

The hardness value of the S45C steel disc and SUJ-2 ball tested in the current experiment were $230.7 \mathrm{Hv}$ and $772 \mathrm{H}_{v}$, respectively. The maximum contact pressure range of the contact point between the current test specimen based on elastic Hertz contact theory is $2700 \mathrm{MPa}$ to $3400 \mathrm{MPa}$, which is higher than the contact pressure of $950 \mathrm{MPa}$ in earlier studies [6,9]. It can be expected that the relatively low hardness of disc caused two-body abrasion on its surfaces under the higher contact pressure in the current experiments. When the hardness value of contact materials are high, wear loss generally decreases when using a lubricant with ND particle regardless of the contact pressure level. For example, Elomaa et al. conducted wear tests of stainless steel ball and disc using lubricants with ND particles at a maximum contact pressure of $2.2 \mathrm{GPa}$ [10]. They reported that the wear loss generally decreased as the ND concentration increased from $0 \mathrm{wt} . \%$ to $2.2 \mathrm{wt} . \%$. This phenomenon is likely to occur in the present experimental result. Therefore, care is needed when utilizing a lubricant with ND particles with soft materials.

Fig. 3 shows the maximum, minimum and average wear losses as a function of the ND concentration under the four loading conditions. From this figure, the lubricant with $0.0075 \mathrm{wt} . \%$ exhibits slightly better anti-wear performance as compared to that of the lubricant without ND particles in the current experimental conditions. However, the lubricants with ND particles tend to exhibit more wear loss due to abrasive wear as compared to the lubricant without ND particles at certain contact forces. Wear test results are generally affected by the testing temperature, specimen surface roughness, ND particle size and concentration, among other factors. Therefore, various experimental data at various contact pressures are necessary in order to commercialize the lubricant with ND for S45C steel and bearing steel. Specifically, lubricant with ND particles must be used at a certain low contact pressure in order to exhibit ball-bearing effect of the ND particles. Therefore, further experiments on contact forces lower than $30 \mathrm{~N}$ are necessary.

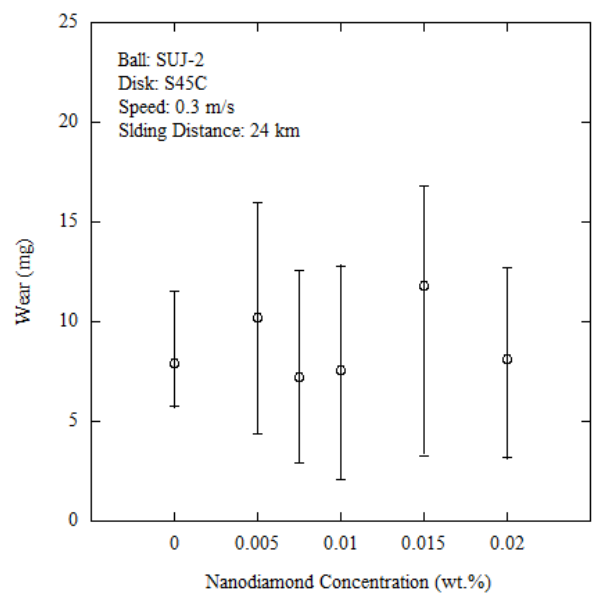

Fig. 3 Wear loss of the disc as a function of the ND concentration after the $24 \mathrm{~km}$ wear test

The friction coefficients arising during the entire process for the six lubricants were determined at contact forces of $30 \mathrm{~N}, 40 \mathrm{~N}, 50 \mathrm{~N}$ and $60 \mathrm{~N}$. Fig. 4 shows the changes in the friction coefficients of the lubricants with and without nanoparticles at a contact force of $30 \mathrm{~N}$. As shown in the figure, the friction coefficients always varied with the sliding distance during the tribological test. The friction coefficient generally increased as the sliding distance increased. The average friction coefficients corresponding to different loading conditions were determined according to the sum of friction coefficient divided by number of data instance, as summarized in Table 1. The average friction coefficient of the lubricant without ND under contact force was 0.127 . In addition, the coefficients of the lubricant at levels of $0.005 \mathrm{wt} . \%, 0.0075 \mathrm{wt} . \%, 0.01 \mathrm{wt} \%, 0.015 \mathrm{wt} . \%$ and $0.02 \mathrm{wt} . \%$ at an identical amount of contact force were $0.130,0.134,0.137,0.139,0.134$, respectively. These finding indicate that the average friction coefficient increased as the ND particle concentration increased, suggesting that the abrasive wear occurring between the ball and disc caused an increment of the friction coefficient.

Fig. 5 shows the maximum, minimum and average friction coefficient results of the four aforementioned contact forces as a function of the ND particle concentrations. As shown in this figure, the lowest friction coefficient was realized when the ND particle concentration in the $5 \mathrm{~W}-40$ lubricant was 0.0075 wt. $\%$ under the present contact force conditions. 


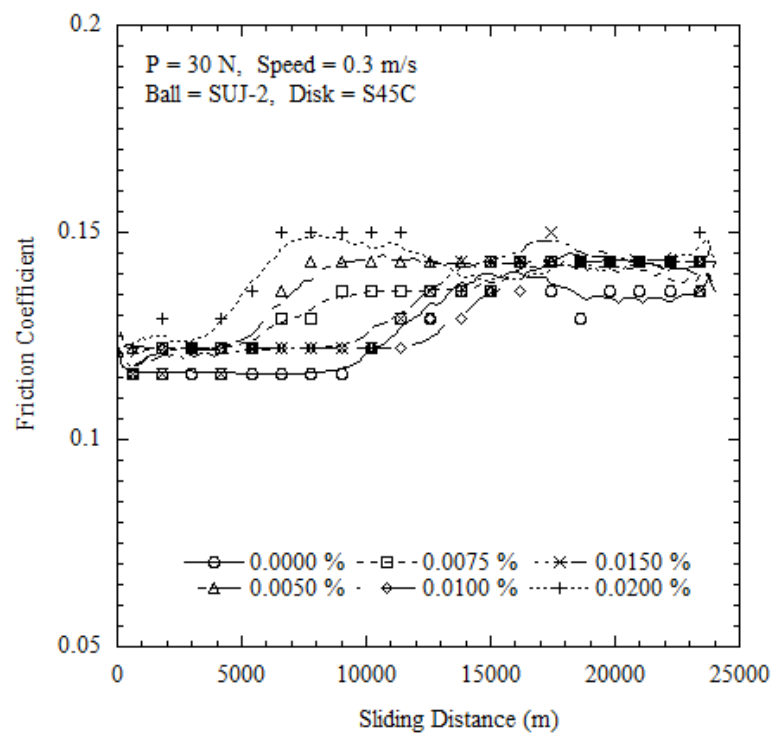

Fig. 4 Variation of the friction coefficient with oils with different ND concentration under an applied load of $30 \mathrm{~N}$

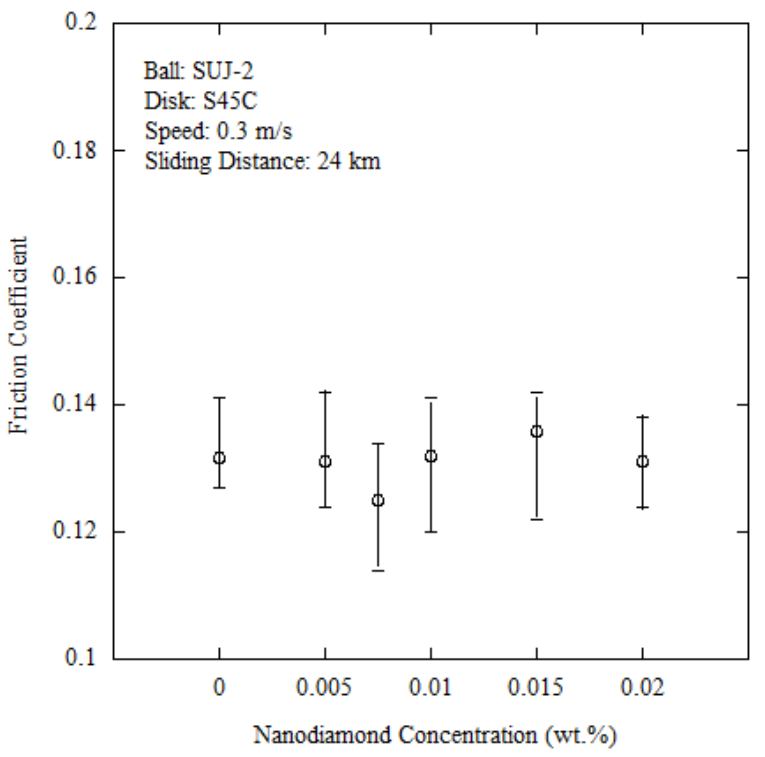

Fig. 5 Variation of the friction coefficient with oils with different ND concentrations

Table 1 Average friction coefficient with oils containing different ND concentrations under various contact forces

\begin{tabular}{|c|c|c|c|c|}
\hline $\begin{array}{c}\text { ND concent. } \\
\text { (wt.\%) }\end{array}$ & $30 \mathrm{~N}$ & $40 \mathrm{~N}$ & $50 \mathrm{~N}$ & $60 \mathrm{~N}$ \\
\hline 0 & 0.127 & 0.141 & 0.129 & 0.130 \\
\hline 0.0050 & 0.130 & 0.129 & 0.142 & 0.124 \\
\hline 0.0075 & 0.134 & 0.125 & 0.127 & 0.114 \\
\hline 0.0100 & 0.137 & 0.130 & 0.141 & 0.120 \\
\hline 0.0150 & 0.139 & 0.140 & 0.142 & 0.122 \\
\hline 0.0200 & 0.134 & 0.138 & 0.128 & 0.124 \\
\hline
\end{tabular}

SEM images of worn surfaces without and with $0.02 \mathrm{wt} . \%$ of ND particles added to the lubricants are shown in Fig. 6(a) and (b), respectively. In the lubricant without ND particles, the trace of the worn surfaces are smoother than those of the $0.02 \mathrm{wt} \%$ ND particles. In the tribological test, the ND particles make the wear tracks of the steel rougher by scratching the contact asperities and thus increasing the friction and wear. Intensive investigations are necessary to explore this connection. 
The tribological characteristics of a lubricant with ND particles generally depend on the contact pressure. In a low contact pressure regime, the Mending effect arises, where wear cracks become filled with particle, thus restraining the crack propagation phenomenon. Meanwhile, in the high pressure regime, contact pressure is known to cause ND particles to be deposited onto the rubbing surface. The deposition of ND particles on the worn surface forms a protective film which prevents direct contact between the rubbing surfaces, improving the anti-wear properties, and reducing the friction coefficient. However, lubricants with ND particles tend to exhibit inferior wear and friction performance capabilities compared to lubricants without ND particles in some current experiment cases. Relatively low hardness of disc specimen in use and high contact pressure generally lead to two-body abrasion on the surfaces, resulting in increased wear loss and friction. Thus, the optimal ND concentration is $0.0075 \mathrm{wt} . \%$ of ND particles in the $5 \mathrm{~W}-40$ lubricant in view of the friction reduction and antiwear abilities of the lubricant. Further investigations of the optimal concentration of ND particles under various loadings, sliding speeds, oil temperatures and sliding distances are required in order to commercialize lubricant with ND particles.

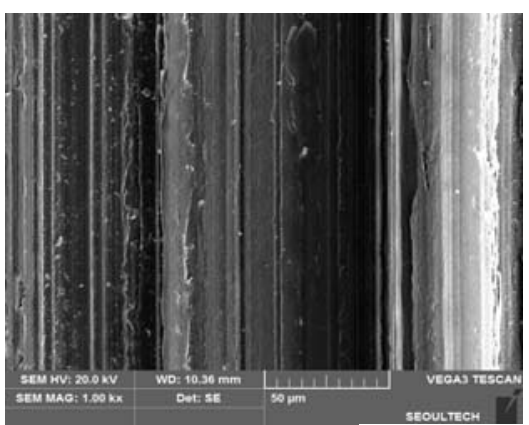

(a)

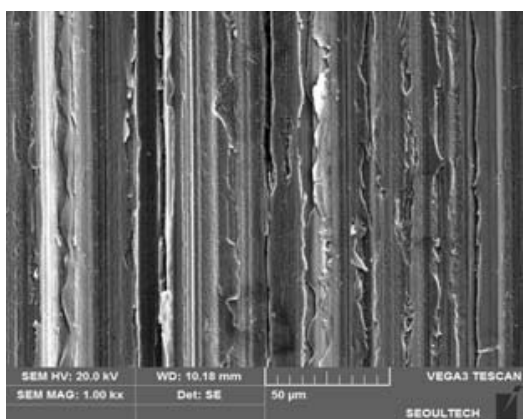

(b)

Fig. 6 SEM micrographs of the wear track after the friction test using engine oil with (a) $0 \%$ and (b) 0.02 wt. $\%$ ND under an applied load of $60 \mathrm{~N}$

\section{CONCLUSION}

Pin-to-disc wear tests were conducted in order to investigate the wear characteristics of lubricants with ND particles using SUJ-2 steel balls and SM45C steel discs The applied loads were $30 \mathrm{~N}, 40 \mathrm{~N}, 50 \mathrm{~N}$ and $60 \mathrm{~N}$, and the sliding speed was $0.3 \mathrm{~m} / \mathrm{s}$ in all case. The wear tests were run at a sliding distance of $24 \mathrm{~km}$. The friction coefficients and wear losses of SM45C specimens were tested with various commercial oils with different ND concentrations ranging from 0 to $0.02 \mathrm{wt} . \%$. The addition of ND particles to a commercial type of oil (5W-40) was found to reduce the wear loss of SM45C steel. For this type of steel, the best concentration was found to be 0.0075 wt. $\%$. The addition of ND particles to the commercial oil was found to reduce the coefficient of friction for SM45C steel. The average minimum coefficient of friction was obtained at a $0.01 \mathrm{wt} . \%$ concentration. Finally, ND particles as a solid additive in oil lubricants were found to improve the tribological behavior of SM45C carbon steel. For the SM45C steel, the best concentration was found to be $0.0075 \mathrm{wt} . \%$ with reference to the friction coefficient and wear loss. Additional investigations of the optimal concentration of ND particles under various loadings, sliding speeds, oil temperatures and sliding distances are required.

\section{ACKNOWLEDGMENT}

This study was financially supported by the Research Program funded by the Seoul National University of Science and Technology.

\section{REFERENCES}

[1] S.H. Jun, Y.R. Uhm, C.K. Rhee, "Tribology properties of nanodiamond dispersed engine oil", J. Kor. Powder Metall. Institute, vol. 18, no. 5, pp. 417-422, 2011

[2] H.L. Yu, Y. Xua, P.J. Shi, H.M. Wang, Y. Zhao, B.S. Xu, Z.M. Bai, "Tribological behaviors of surface-coated serpentine ultrafine powders as lubricant additive", Trib. Int., vol. 43, pp. 667-675, 2010.

[3] B.S. Zhang, B.S. Xu, Y. Xu, F. Gao, P.J. Shi, Y.X. Wu, "Cu nanoparticles effect on the tribological properties of hydrosilicate powders as lubricant additive for steel-steel contacts", Trib. Int., vol. 44, pp. 878-886, 2011.

[4] R. Chou, A. H. Battez, J.J. Cabello, J.L. Viesca, A. Osorio, A. Sagastume, "Tribological behavior of polyalphaolefin with the addition of nickel nanoparticles", Trib. Int., vol. 43, pp. 2327-2332, 2010.

[5] Y.Y. Wu, W.C. Tsui, T.C. Liu, "Experimental analysis of tribological properties of lubricating oils with nanoparticle additives", Wear, vol. 262, pp. 819-825, 2007.

[6] H.Y. Chu, W.C. Hsu, J.F. Lin, "The anti-scuffing performance of diamond nano-particles as an oil additive”, Wear, vol. 268, pp. 960967, 2010.

[7] C.C. Chou, S.H. Lee, Rheological behavior and tribological performance of a nanodiamond-dispersed lubricant, J. Mater. Process. Tech. vol. 201 pp. 542-547, 2008. 
[8] L. Joly-Pottuz, N. Matsumoto, H. Kinoshita, B. Vacher, M. Belin, G. Montagnac, J.M. Martin, N. Ohmae, "Diamond-derived carbon onions as lubricant additives", Trib. Int., vol. 41, pp. 69-78, 2008.

[9] H.S. Kim, J.W. Park, S.M. Park, J.S. Lee, Y.Z Lee, "Tribological characteristics of paraffin liquid with nanodiamond based on the scuffing life and wear amount", Wear, vol. 301, pp. 763-767, 2013.

[10] O. Elomaa, T. Hakala, V. Myllymäki, J. Oksanen, H. Ronkainen, V. Singh, J. Koskinen, "Diamond nanoparticles in ethylene glycol lubrication on steel-steel high load contact”, Diamond \& Related Mat, vol. 34 pp. 89-94, 2013. 